\title{
Evaluation of secondary post-traumatic stress disorder symptoms in the spouses of chemical warfare victims 20 years after the Iran-Iraq war
}

\author{
Khodabakhsh Ahmadi, ${ }^{1}$ Mahmood Reshadatjoo, ${ }^{2}$ GholamReza Karamii, Nariman Sepehrvand, ${ }^{2}$ \\ Pegah Ahmadi, $^{2}$ Shahrzad Bazargan-Hejazi ${ }^{3}$
}

The Psychiatrist (2011), 35, 168-175, doi: 10.1192/pb.bp.110.029587

\author{
'Baqiatallah University of Medical \\ Sciences, Tehran, Iran; ${ }^{2}$ Urmia \\ University of Medical Sciences, Urmia \\ Iran; ${ }^{3}$ Charles Drew University of \\ Medicine and Science and University \\ of California, Los Angeles, USA \\ Correspondence to Khodabakhsh \\ Ahmadi (k.ahmadi@bmsu.ac.ir) \\ First received 18 Feb 2010, final \\ revision 19 Jun 2010, accepted \\ 13 Oct 2010
}

\begin{abstract}
Aims and method Post-traumatic stress disorder (PTSD) has been reported in $90 \%$ of chemical warfare victims in previous studies. An individual's traumatic experience(s) may affect the lives of other family members as well. This crosssectional case-control study compared the prevalence of PTSD symptoms in the husbands, the secondary PTSD symptoms in the wives and also aimed to identify if there was an association between the PTSD symptoms of the couples in the case group. Cases were 150 husband-wife couples where husbands were civilians exposed to chemical warfare; the controls were 156 husband-wife couples where there was no such exposure. Both cases and controls were recruited from Sardasht in Iran; this Kurdish city was attacked by four $250 \mathrm{~kg}$ sulphur mustard warheads in June 1987.

Results Across three sets of cut-off points for the Mississippi Scale for CombatRelated PTSD symptomotology $(<120$ and $\geqslant 121$; $<106$ and $\geqslant 107$; and $<65$, 65130 and $>130$ ) wives in the case group demonstrated higher rates of PTSD symptoms than did those in the control group; the difference was statistically significant. Furthermore, husbands in the case group had a significantly higher overall mean score $(123.0$ (s.d. $=17.2))$ than the husbands in the control group (112.3 (s.d. $=21.7) ; P<0.001, t=4.80)$. There was no statistically significant association between the overall PTSD score of the husbands in the case group with that of their
\end{abstract} wives $(P=0.274$, correlation coefficient 0.092).

Clinical implications Husbands who were exposed to the chemical agents reported higher PTSD symptoms and there were higher rates of PTSD symptoms among the wives of individuals who were exposed to chemical warfare. Study results suggest the need for coordinated treatments, policy efforts and interventions to improve the wellbeing of chemical warfare victims and their caregiver wives.

Declaration of interest None.
Sulphur mustard gas is a chemical warfare agent that was widely used during the First and Second World Wars, and more recently by the Iraqi forces during the 8-year IranIraq war. ${ }^{1,2}$ Sulphur mustard gas is an extremely dangerous poison that attacks its victims both internally and externally. The symptoms include eye irritation, inflammation and blindness. It also affects the skin and causes itchy redness that leads to blistering. It assaults the respiratory system by stripping off the mucous membrane of the bronchial tubes, causing a hoarse throat, shortness of breath, coughing and a choking sensation. The digestive system is also affected with abdominal pain, diarrhoea, fever and vomiting. ${ }^{3}$ Once exposed to a certain dosage, mustard gas can kill its victim in 4-5 weeks. For many, however, it leaves a lifetime of physical disability. ${ }^{4}$
Approximately 20000 Iranian troops and civilians were killed by mustard gas attacks during the Iran-Iraq war, and another 80000 were injured. This is about a quarter of the number of deaths caused by chemical weapons during the First World War. ${ }^{5}$ The casualties of mustard gas was especially pronounced for the soldiers and civilians in the border towns and villages of the north-western region of Iran. $^{6}$

Approximately 34000 Iranians sustained exposure to this chemical warfare agent, ${ }^{7,8}$ which is now costing the nation's healthcare system about $\$ 37$ million annually. ${ }^{9}$ Sardasht is a small city in the West Azarbaijan province in north-western Iran, $10 \mathrm{~km}$ from the Iran-Iraqi border. This city was exposed to both chemical and non-chemical bombardments (60 times) during the Iran-Iraq war. In June 1987, this Kurdish town was attacked with four $250 \mathrm{~kg}$ 
sulphur mustard warheads that exploded in the centre of the town, injuring approximately 4500 residents. ${ }^{10}$

Several studies have investigated the physical health consequences of exposure to mustard gas., ${ }^{1,8,11}$ However, there is little research evaluating the mental health outcomes of such exposure. In a sample of Second World War veterans who were exposed to mustard gas, nearly a third met the criteria for full current post-traumatic stress disorder (PTSD) 50 years after their exposure. ${ }^{12-15}$ Tavalaei et al reported PTSD in $90 \%$ of Iranian chemical warfare victims. ${ }^{7}$ Romano et al demonstrated anxiety disorders in $57 \%$ of soldiers exposed to chemical and biological agents. ${ }^{16}$ Anxiety disorders were reported to be more frequent in Iranian chemical warfare victims in comparison with other disabled veterans. ${ }^{17-19}$ Post-traumatic stress disorder not only affects the quality of life of war veterans but also creates a huge burden for their caregivers and families. ${ }^{20}$ Several studies have pointed to the mental health problems in the family members of disabled veterans. ${ }^{21}$ Secondary traumatisation refers to a therapist's reactions to clients' often painful and graphic traumatic experiences. ${ }^{22}$ The experience of secondary trauma, or the spread of trauma from the vicitm to those close to the vicitm, ${ }^{23}$ has been reported by mental health clinicians ${ }^{24}$ and healthcare workers who are involved with the care of traumatised individuals, including victims of child abuse,${ }^{25}$ interpersonal violence, $^{26,27}$ torture $^{28}$ and large-scale disasters. ${ }^{29-31}$ Compassion fatigue or secondary traumatic stress are two other terms that refer to the psychogenic reactions to the traumatic experience of a person who is important to us (Box 1). ${ }^{32,33}$

Psychological and physical symptoms of exposure to secondary trauma are similar to those experienced by people who have been directly affected by a traumatic event including nightmares about the victim, insomnia, irritability, loss of emotions, fatigue, ${ }^{34}$ headache, hearing problems, predisposition to infectious diseases and substance misuse. ${ }^{35,36}$ The experience of caregiver burden has been investigated extensively. ${ }^{34,37-45}$ However, the prevalence of secondary PTSD among wives of chemical warfare victims has not been studied. Female spouses of war

\section{Box 1 Definition of terms}

- Secondary post-traumatic stress disorder (PTSD): presenting PTSD-like symptoms (including nightmares, insomnia, irritability, loss of emotions, fatigue, headache etc) without directly have experienced a traumatic event

- Civilian: an ordinary individual who may have or have not been exposed to the chemical warfare during the 8-year Iran and Iraq war

- War victim: any civilian who has been, physically or mentally affected by a war

- Chemical war victim: a civilian male war victim who survived exposure to chemical warfare during the 8-year Iran and Iraq war

- Case group: a husband-wife couple where the husband was a chemical war victim

- Control group: a husband-wife couple where the husband was a civilian who was not exposed to chemical warfare victims, because of their close contact with their husbands, are among the groups at-risk for secondary traumatic stress. ${ }^{46}$ Often the role of such female spouses is to preserve family stability and regulate family functioning, which subject them to extra pressure. ${ }^{36}$ In Iran, it is within the expected cultural norm that the male victims of chemical warfare live at home with the assistance of their wives. The need for respite for these wives is often not recognised until their own health begins to deteriorate. The mental wellbeing and physical strength of these wives is essential for providing ongoing care in the home and avoiding or postponing institutionalisation. Therefore, identification of secondary PTSD symptoms among these female spouses should be considered in the development of strategies to offset caregiver burden.

This study aimed to compare the prevalence of PTSD symptoms among the husbands in case and control groups; to compare the prevalence of secondary PTSD symptoms among the wives in case and control groups; and to identify if there is an association between the PTSD symptoms of the couples in the case group. We hypothesised that there would be a higher level of PTSD symptoms among husbands in the case group than in the control group; there would be a higher level of secondary PTSD symptoms among the wives in the case group than in the control group; and there would be a direct association between the PTSD symptoms of the husbands and wives in the case group.

\section{Method}

\section{Participants}

This was a cross-sectional case-control study. For the selection of cases, study staff reviewed all the available records in the Foundation of Martyrs and Veterans Affairs in Sardasht to identify male civilians who were chemical war victims. There were 1336 registered male chemical war victims in Sardasht. They were recruited for the initial screening. The screener included items from the DSM-IV-TR ${ }^{47}$ criteria A (stressor) for PTSD ${ }^{10}$ assessing if during exposure to the war: the chemical war victim was confronted with an actual or threat of death or injury; and if the individual expressed feeling of hopelessness and fear. The people who screened positive on both items were recruited for the study along with their wives. Next, the husband-wife couples were screened for participation eligibility based on the following criteria: history of chronic disease or a malignancy; history of chronic diseases or malignancies among other members of the family; presence of any other chemical war victims or disabled persons living with the family. Couples who responded 'no' to all the aforementioned criteria were eligible to take part in the study. Of the 176 case-couples who met study eligibility criteria, $150(85.2 \%)$ agreed to sign an informed consent form and participated in the study. For selection of couples in the control group, systematic random sampling was used and we selected 156 couples from a list of residents in Sardasht. The control couples met the same aforementioned eligibility criteria and were matched with the case couples by age, direct exposure to the destruction and material losses of war as a traumatic life event and indirect exposure 
to socioeconomic disadvantages of war and military drafting of family members and/or friends. The difference between the case and control couples had to do with the exposure of the husband in the case couples to chemical warfare during the Iraq-Iran war.

\section{Outcome measure}

We used the Mississippi Scale for Combat-Related PTSD $(\mathrm{M}-\mathrm{PTSD})^{48}$ to measure the study outcome variable. The M-PTSD was originally developed by Keane and colleagues $^{48}$ and was later revised by Norris et al. ${ }^{49}$ The M-PTSD is a 39-item self-report measure of combat-related PTSD. It takes 10-15 min to administer, and includes items related to: re-experiencing symptoms of the traumatic event, such as intrusive memories and recurrent nightmares, which reflects DSM-IV criterion B for PTSD; engaging in protective reactions, such as avoidance of the stimuli associated with the trauma and emotional numbing, which reflects DSM-IV criterion C for PTSD; and experiencing arousal symptoms, such as startled responses and hypervigilance, which reflects DSM-IV criterion D for PTSD.

Respondents were asked to rate how they felt about each item using 5-point Likert-scale response categories. Responses were summed to provide an index of PTSDsymptom severity score ranging from 39 to 195; a higher score indicating more severe symptoms of PTSD. The original 35-item scale was tested among samples of veterans seeking treatment, and has been shown to have high reliability (Cronbach $\alpha=94)^{48}$ and validity. ${ }^{50}$ Goodarzi $^{51}$ validated the Persian/Farsi version for the Iranian population (2003) and reported high internal consistency (Cronbach $\alpha=0.91$ ) and cross-cultural validity. Keane et al reported that a cut-off score of 107 has a sensitivity of $93 \%$ and a specificity of $89 \% .{ }^{48}$ However, it has been reported that the scale is vulnerable to faking and therefore a cut-off score of 121 has been suggested. ${ }^{52}$ Although the sensitivity of this cut-off score is good (0.95), its specificity is compromised (0.45). A cut-off score that would optimise both sensitivity and specificity has not been reported. ${ }^{53}$

\section{The Bonyad-e Janbazan Morbidity Index}

The Bonyad-e Janbazan Morbidity Index (www.dolat.ir/ NSite/FullStory/?id=189580) is a formal index developed by the Bonyad-e Janbazan Foundation; a national organisation responsible for the social, physical and mental health and welfare of war-induced disabled veterans, civilians, and their immediate families. This index was developed using objective data (i.e. physical symptoms) extracted from the medical charts and/or personal interviews with the chemical war victims. The Morbidity Index is reported as a percentage and determines the veterans' degree of morbidity and disability. Based on this index, chemical war victims who score $\geqslant 25 \%$ are eligible for physical, psychological, social and economic assistance. According to a report by Bonyad-e Janbazan, there are currently 1400 chemical war victims of whom 400 score $\geqslant 25 \%$ on the Morbidity Index. These victims and their families receive medical, social and economic assistance from this organisation.

\section{Statistical analysis}

We used SPSS software version 11.5 for Windows to calculate measures of central tendency including mean, median and measures of dispersion such as standard deviation to provide univariate analysis of the study's main variables. In order to test the study hypotheses, we used independent $t$-tests, Pearson's correlation and chi-squared tests. $P \leqslant 0.05$ was set as the statistically significant level.

\section{Results}

In this study we set out to compare the prevalence of PTSD symptoms among the husbands in case and control groups. We anticipated detecting a higher level of PTSD symptoms

\begin{tabular}{|c|c|c|c|c|}
\hline & $n$ & Mean (s.d.) & $t$ & $P$ \\
\hline $\begin{array}{l}\text { Total score } \\
\text { Case } \\
\text { Control }\end{array}$ & $\begin{array}{l}148 \\
156\end{array}$ & $\begin{array}{l}123.06(17.19) \\
112.29(21.73)\end{array}$ & 4.80 & 0.001 \\
\hline $\begin{array}{l}\text { Frequently haunted by memories } \\
\text { Case } \\
\text { Control }\end{array}$ & $\begin{array}{l}150 \\
156 \\
\end{array}$ & $\begin{array}{l}32.36(7.32) \\
28.62(7.71)\end{array}$ & 4.33 & 0.001 \\
\hline $\begin{array}{l}\text { Problems with personal relationships } \\
\text { Case } \\
\text { Control }\end{array}$ & $\begin{array}{l}148 \\
156 \\
\end{array}$ & $\begin{array}{l}29.54(7.26) \\
25.50(7.18)\end{array}$ & 4.55 & 0.001 \\
\hline $\begin{array}{l}\text { Problems in controlling emotional feelings } \\
\text { Case } \\
\text { Control }\end{array}$ & $\begin{array}{l}150 \\
156\end{array}$ & $\begin{array}{l}31.52(4.67) \\
29.21(8.79)\end{array}$ & 2.85 & 0.005 \\
\hline $\begin{array}{l}\text { Lack of depression } \\
\text { Case } \\
\text { Control }\end{array}$ & $\begin{array}{l}148 \\
156\end{array}$ & $\begin{array}{l}29.55(6.39) \\
28.94(8.56)\end{array}$ & 0.75 & 0.48 \\
\hline
\end{tabular}

PTD, post-traumatic stress disorder. 


\begin{tabular}{|c|c|c|c|}
\hline Cut-off points on M-PTSD & $\begin{array}{l}\text { Case group, } n(\%) \\
\quad(n=150)\end{array}$ & $\begin{array}{l}\text { Control group, } n(\%) \\
\quad(n=156)\end{array}$ & $P$ \\
\hline$>121$ & $109(72.6)$ & $55(35.2)$ & 0.002 \\
\hline$>107$ & $139(92.6)$ & $94(60.2)$ & 0.009 \\
\hline
\end{tabular}

\begin{tabular}{|c|c|c|c|c|}
\hline & & \multicolumn{3}{|c|}{ M-PTSD score } \\
\hline & Mild, <65: $n(\%)$ & Moderate, 65-130: $n(\%)$ & Severe, $>130: n(\%)$ & $P$ \\
\hline Group & & & & 0.001 \\
\hline Case & $2(1.4)$ & $140(96.6)$ & $3(2.1)$ & \\
\hline Control & $40(25.6)$ & $113(72.4)$ & $3(1.9)$ & \\
\hline
\end{tabular}

among the husbands in the case group than in the control group. Table 1 presents the mean differences for the overall PTSD symptoms in these groups. Husbands in the case group had a significantly higher overall mean score (123.0, s.d. = 17.2) than the husbands in the control group (112.3, s.d. $=21.7 ; P<0.001, t=4.80)$. Table 1 also reveals that there are statistically significant $(P<0.05)$ differences between the PTSD subscale mean scores of the husbands in the case group compared with those in the control group ('frequently haunted by memories' $32.4 v$. 28.2; 'problems with personal relationships' 29.5 v. 25.5; 'problems in controlling emotional feelings' 31.5 v. 29.1; and 'lack of depression' 29.5 v. 28.9 (Table 1)).

We also investigated whether the wives in the case group would report higher levels of PTSD symptoms compared with their counterparts in the control group. Using chi-squared tests of association, Tables 2 and 3 demonstrate that there are differences between the two groups across three sets of cut-off points for PTSD $(<120$ and $\geqslant 121$; $<106$ and $\geqslant 107,<65,65-130$ and $>130$ ). We used different sets of cut-off points to factor in the vulnerability of M-PTSD to faking reported in the literature. ${ }^{52}$ Across all cut-off points, wives in the case group demonstrated higher rates of PTSD symptoms than their counterparts in the control group, and the difference between the two groups was statistically significant. Using the chi-squared test of association for the $<120$ and $\geqslant 121$ cut-off score, the rates between the case and control groups were $72.6 \%$ v. $35.2 \%(P<0.002)$. For the $<106$ and $\geqslant 107$ cut-off score, $92 \%$ of those in the case group reported PTSD symptoms, whereas $60.2 \%$ of the control group reported such symptoms (Table 2).

For the current study, a PTSD score of $\leqslant 65$ was labelled as 'mild', 65-130 as 'moderate', and >130 as 'severe' symptoms. Nearly all the wives in the case group reported 'moderate' PTSD symptoms (96.6\%). For the control group, this rate was $72.4 \%$. The difference between the two groups was statistically significant $(P<0.001)$ (Table 3).

Table 4 shows the mean scores for the overall PTSD symptoms and its subscales for wives in both groups. Wives in the case group had a significantly higher overall mean score $(128.68$, s.d. $=12.67)$ than their counterparts in the control group (111.27, s.d. $=21.21 ; P<0.001, t=8.71$ ). Similarly, we detected significantly $(P<0.001)$ higher mean scores for all the M-PTSD subscales among the wives in the case group in comparison with the control group: 'frequently haunted by memories' 35.4 v. 29.1; 'problems in personal relationships' 29.3 v. 26.4; 'problems in controlling emotional feelings' 32.9 v. 28.8; and 'lack of depression' 31.1 v. 26.9 (Table 4).

We also expected to detect a direct association between the husbands' report of PTSD symptoms and that of their wives in the case group. However, there was none based on the overall PTSD score $(P=0.274$, correlation coefficient 0.092). Furthermore, we could not detect any statistically significant association between the overall PTSD scores of the wives and the disability scores of their husbands calculated based on the Bonyad-e Janbazan Morbidity Index, as described in the Method (Table 5).

\section{Discussion}

\section{Main findings}

Our study showed that male civilians who were directly exposed to chemical warfare during the Iraq-Iran war had higher level of PTSD symptoms compared with their nonexposed counterparts. Tavalaei et al also reported that the prevalence of PTSD symptoms among Iranian chemical warfare victims was as high as $90 \% .^{7}$ Several other studies have demonstrated high rates of PTSD symptoms among war veterans. ${ }^{10,12,14,15}$ This is an important finding since PTSD has been reported to be a risk factor for developing dementia, ${ }^{54}$ diminished quality of life ${ }^{55,56}$ problems readjusting to community life $;^{57}$ and more alcohol consumption and illicit drug use. ${ }^{56}$ Coordinated treatment and policy efforts and intervention procedures could improve the functioning and well-being of chemical war victims. Moreover, clinicians should be alert that chemical war victims with PTSD could suffer from comorbid medical problems and undertake health-compromising risky behaviours. Therefore, they should recommend regular 


\begin{tabular}{|c|c|c|c|c|}
\hline & $n$ & Mean (s.d.) & $t$ & $P$ \\
\hline $\begin{array}{l}\text { Overall score } \\
\text { Case } \\
\text { Control }\end{array}$ & $\begin{array}{l}145 \\
156 \\
\end{array}$ & $\begin{array}{l}128.68(12.67) \\
111.27(21.21)\end{array}$ & 8.71 & $<0.001$ \\
\hline $\begin{array}{l}\text { Frequently haunted by memories } \\
\text { Case } \\
\text { Control }\end{array}$ & $\begin{array}{l}147 \\
156 \\
\end{array}$ & $\begin{array}{l}35.42(5.89) \\
29.14(7.39) \\
\end{array}$ & 8.19 & $<0.001$ \\
\hline $\begin{array}{l}\text { Problems with personal relationships } \\
\text { Case } \\
\text { Control }\end{array}$ & $\begin{array}{l}148 \\
156 \\
\end{array}$ & $\begin{array}{l}29.35(3.95) \\
26.39(7.81) \\
\end{array}$ & 4.18 & $<0.001$ \\
\hline $\begin{array}{l}\text { Problem in controlling emotional feelings } \\
\text { Case } \\
\text { Control }\end{array}$ & $\begin{array}{l}150 \\
156 \\
\end{array}$ & $\begin{array}{l}32.95(3.80) \\
28.85(8.49) \\
\end{array}$ & 5.47 & $<0.001$ \\
\hline $\begin{array}{l}\text { Lack of depression } \\
\text { Case } \\
\text { Control }\end{array}$ & $\begin{array}{l}145 \\
156\end{array}$ & $\begin{array}{l}31.08(4.74) \\
26.87(8.37)\end{array}$ & 5.42 & $<0.001$ \\
\hline
\end{tabular}

physical check-ups, offer regular screening for substance misuse and provide adequate referrals. ${ }^{58}$

As demonstrated in the results, the rate and intensity of PTSD symptoms among wives in the case group were significantly higher than those in the wives in the control group where husbands were not affected by chemical warfare. This pattern was evident by higher representation of wives in the case group across cut-off points ( $>121$ and $>107$; $P<0.5)$. Moreover, nearly all the wives in the case group (96.6\%) reported suffering from moderate or severe PTSD symptoms. In the control group, this rate was $72.4 \%$, and the difference between the two groups was statistically significant $(P<0.5)$. Also, across all the PTSD symptom subscales, including 'frequently haunted by memories', 'problems in personal relationships', 'inability to control emotional feelings' and 'lack of depression', the mean scores for the PTSD symptoms of the wives in the case group were higher than the mean scores of their counterparts in the control group $(P<0.5)$ (Table 3$)$. These findings corroborate previous empirical results that report a high level of secondary PTSD among the spouses of warfare victims. ${ }^{59}$ It also adds to the existing knowledge by highlighting the extra burden that the wives of chemical warfare victims endure. The physical and psychological consequences of these burdens, if left uncontrolled or unchecked, can have significant adverse health consequences not only for the wife as a caregiver but also for the patient (i.e. husband) if and when proper caregiving is threatened. Therefore, identification of the level and intensity of secondary PTSD symptoms among wives of chemical war victims should be the first step towards the development of strategies to offset caregiver burden among this group. In this respect, primary care physicians should keep wives of chemical war victims under their constant attention, regularly screen them for undetected mental, emotional and physical stress, and provide them with proper referrals as needed. Homebased interventions can provide creative and culturally accepted options to overcome the burden of care for this population. It could also be of value in lowering medical costs and sustaining effective care for chemical war victims and their wives.
Furthermore, family psychologists who provide care to chemical war victims must also address the trauma experienced by these individuals' wives. They should assist both of them so that they recover from their ordeals together. ${ }^{34}$ The salience of effective social supports and the benefits of empowering wives of war victims to manage the sociopsychological burdens of caregiving are included among the interventions suggested. ${ }^{60}$ These types of therapeutically induced interventions may provide a buffer against relationship distress caused by caregiver burden. ${ }^{39}$

Nevertheless, it is important to note the high rate of PTSD-like symptoms in the wives of non-affected husbands. This could be attributed to these women's experiences of the war's brutality and the overall life-threatening situation in Sardasht during the war. As was mentioned earlier, all the participants in the study were civilians (residents) of Sardasht who were exposed to extensive bombardments during the Iraq-Iran war and its direct and indirect socioeconomic consequences, with the exception that husbands in the case group were exposed to chemical warfare. The high rate of PTSD-like symptoms among the wives in the control group therefore could be the longlasting result of a war that left women living in Sardasht vulnerable to the symptoms of PTSD. Further studies are needed to identify other sociopsychological characteristics

\begin{tabular}{|c|c|c|c|}
\hline Table 5 & $\begin{array}{l}\text { Distribution } \\
\text { Related Post } \\
\text { (M-PTSD) } \\
\text { warfare victi } \\
\text { percentage } \\
\text { Morbidity In }\end{array}$ & $\begin{array}{l}\text { Mississippi Scale for } \\
\text { aumatic Stress Disor } \\
\text { res in spouses of che } \\
\text { based on husbands' } \\
\text { ording to the Bonyad } \\
\text { x }\end{array}$ & $\begin{array}{l}\text { bat- } \\
\text { bidity } \\
\text { anbazan }\end{array}$ \\
\hline \multicolumn{2}{|c|}{ Husbands' morbidity, \% } & $\begin{array}{c}\text { Wives' M-PTSD score, } \\
\text { mean (s.d.) }\end{array}$ & $P$ \\
\hline \multicolumn{2}{|l|}{$<20$} & $128.01(1.89)$ & \multirow{4}{*}{$>0.05$} \\
\hline \multicolumn{2}{|l|}{$20-30$} & $126.37(2.12)$ & \\
\hline \multicolumn{2}{|l|}{$30-40$} & $128.61(3.11)$ & \\
\hline \multicolumn{2}{|l|}{$>40$} & $134.52(3.46)$ & \\
\hline
\end{tabular}


of these women and how they may be related to the reporting of PTSD symptoms among women living in Sardasht.

In our study there was no significant relationship between the PTSD symptoms of the wives and that of their husbands in the case group. This finding is similar to the results of Al-Turkait et $a l^{60}$ who studied PTSD among the wives of military men who fought during the first Gulf War in Kuwait and found no association between the level of PTSD in the wives and their husbands. We also did not detect any association between the husbands' degree of morbidity and disability (measured by the Bonyad-e Janbazan Morbidity Index) and the PTSD symptoms of their wives. We tested this secondary hypothesis because findings from the caregiver literature suggest that the level of PTSD symptoms among caregivers most likely depends on the functional status and cognitive function of the individual they are providing care for. ${ }^{61-63}$ Dekel et $a l^{37}$ have suggested that the level of distress among caregivers is more closely associated with perceived caregiver burden than with the level of the primary individual's physical impairment.

Perception of caregiver burden in a country such as Iran where the help-seeking journey starts at home could explain the lack of association between chemical war victims' PTSD symptoms and those of their wives. In Iran, it is within the cultural norms and expecations that women provide proper care for their sick husbands or any other members of the family. Therefore, although providing continued home-care for a chemical war victim can be stressful and straining, for some women this may increase their sense of self-satisfaction, self-efficacy and confidence knowing that they have fulfillied the expected 'female role'. The lack of association could also be reflective of the Islamic beliefs in the lives of wives/caregivers who participated in this study. The spiritual beliefs of these women could have provided them with a coping strategy that disassociates their mental health with that of the husbands. Further imperial investigations are needed to identify protective characteristics in women who care for their husbands who are chemical war victims including spirituality and selfefficacy.

\section{Limitations}

This study has several limitations and therefore the results should be interpreted with caution. First, study data were cross-sectional, limiting our ability to offer any causal inferences about the role of variables that were statistically significant. Second, data for this study were self-reported, therefore subject to response bias. Third, our data lack measures of different physical consequences of exposure to chemical agents in chemical war victims. The severity of the chemical war victims' physical problems was measured only by the 'disability percentage', which had been determined by the Bonyad-e Janbazan Morbidity Index.

However, our study is the first to focus on the secondary PTSD symptoms of the wives of chemical war victims and its association with the PTSD symptoms of their husbands. In this study, we were unable to prove the proposed association between the PTSD symptoms of the chemical war victims and their wives in the case group beyond the probable role of caregiver burden. As mentioned earlier, this could be attributed to a pre-existing mental and psychological vulnerability among the wives because of their exposure to the war. Further investigations are needed to include data about the pre-existing psychological problems of wives in the analysis and interpretation process. These investigations may also benefit from a longitudinal design, inclusion of multi-item risk and protective predictors and the inclusion of social-related variables.

\section{Implications}

In our study, husbands (chemical war victims) in the case group had a significantly higher overall PTSD mean score than the husbands in the control group. Furthermore, wives of chemical war victims demonstrated higher rates of PTSD symptoms than the wives in the control group, and the difference between the two groups was statistically significant. There was no statistically significant association between the overall PTSD score of the husbands in the case group with the PTSD scores of their wives. Studies are needed to explore the characteristics of wives of chemical war victims including their physical, psychological, religious and coping styles, and how they change over time. Results of these studies can help to better understand these and other factors contributing to increased secondary PTSD symptoms or factors that buffer against it. Furthermore, interventions that coordinate clinical care and homebased care for chemical war victims are needed. Proper outcome evaluations of these and other relavent efforts are needed in order to develop more effective caregiver interventions for this population.

\section{About the authors}

Khodabakhsh Ahmadi (PhD) is an associated professor at the Behavioral Sciences Research Center at the Baqiatallah University of Medical Sciences in Tehran, Iran. Mahmood Reshadatjoo (MD) is a research assistant the Students' Research Committee at Urmia University of Medical Sciences in Urmia, Iran. GholamReza Karami (MD) is an assistant professor at the Baqiatallah University of Medical Sciences in Tehran, Iran. Nariman Sepehrvand (MD) is a research fellow at the National Institute of Health Research at Tehran University of Medical Sciences in Tehran, Iran. Pegah Ahmaddi (MD) is a research assistant at the Students' Research Committee at Urmia University of Medical Sciences in Urmia, Iran. Shahrzad Bazargan-Hejazi (PhD) is at the department of psychiatry, Charles Drew University of Medicine and Science, and Department of Psychiatry and Biobehavioral Sciences, Semel Institute for Neuroscience and Human Behavior, University of California, Los Angeles, USA.

\section{Funding}

The Behavioral Sciences Research Center, Baqiatallah University of Medical Sciences, the Students' Research Committee of Urmia University of Medical Sciences and Janbazan Medical and Engineering Research Center provided grants for this study.

\section{References}

1 Ghazanfari T, Faghihzadeh $\mathrm{S}$, Aragizadeh $\mathrm{H}$, Soroush MR, Yaraee $\mathrm{R}$, Mohammad Hassan Z, et al. Sardasht-Iran cohort study of chemical warfare victims: design and methods. Arch Iran Med 2009; 12: 5-14. 
2 Washington Post. Poison gas attack kills Kurds. Washington Post 1988; 24 March.

3 Sidell FR, Urbanetti JS, Smith WJ, Vesicants HC. Medical Aspects of Chemical and Biological Warfare. Textbook of Military Medicine Series. Part 1. Warfare, Weaponry, and the Casualty. Borden Institute, Walter Reed Army Medical Center, 1997.

4 Centres for Disease Control and Prevention. Facts About Sulfur Mustard CDC, 2006 (http://www.bt.cdc.gov/agent/sulfurmustard/basics/ facts.asp).

5 Fassihi F. In Iran, grim reminders of Saddam's arsenal. The Star Ledger 2002; 27 October.

6 Security Council. Report of Specialists Appointed by the Secretary General to Investigate Allegations by the Islamic Republic of Iran concerning the use of Chemical Weapons. United Nations, 1986.

7 Tavallaie SA, Assari S, Najafi M, Habibi M, Ghanei M. Study of sleep disorders among chemical warfare victims [in Persian]. J Mil Med 2004; 6: 241-8.

8 Khateri S, Ghanei M, Keshavarz S, Soroush M, Haines D. Incidence of lung, eye, and skin lesions as late complications in 34,000 Iranians with wartime exposure to mustard agent. J Occup Environ Med 2003; 45 1136-43.

9 Hasani M. Pathology of Chemical Weapons. Chemical warfare victims' Broadcasting Center, 2005

10 Hashemian F, Khoshnood K, Desai MM, Falahati F, Kasl S, Southwick S. Anxiety, depression, and posttraumatic stress in Iranian survivors of chemical warfare. JAMA 2006; 296: 560-6.

11 Zarchi K, Akbar A, Naieni KH. Long-term pulmonary complications in combatants exposed to mustard gas: a historical cohort study. Int J Epidemiol 2004; 33: 579-81.

12 Ford JD, Schnurr PP, Friedman MJ, Green BL, Adams G, Jex S Posttraumatic stress disorder symptoms, physical health, and health care utilization 50 years after repeated exposure to a toxic gas. J Trauma Stress 2004; 17: 185-94.

13 Schnurr PP, Friedman MJ, Green BL. Post-traumatic stress disorder among World War II mustard gas test participants. Mil Med 1996; 161: $131-6$.

14 Schnurr PP, Ford JD, Friedman MJ, Green BL, Dain BJ. PTSD in WWII mustard gas test participants. A preliminary report. Ann N Y Acad Sci 1997; 821: 425-9.

15 Jankowski MK, Schnurr PP, Adams GA, Green BL, Ford JD, Friedman MJ. A mediational model of PTSD in World War II veterans exposed to mustard gas. J Trauma Stress 2004; 17: 303-10.

16 Romano JA, King JM. Psychological casualties resulting from chemical and biological weapons. Mil Med 2001; 166: 21-2.

17 Mohammadi MR, Noori AR. Common psychologic disorders among chemical warfare victims. In Proceedings of the Conference on Neuropsychologic Complications of War, 1993: 147-50. Bonyad Publishing Company, 1993.

18 Haghdadi G, Parchami M. Comparisonal survey of disabled people (Janbazan) with severe psychologic symptoms among two groups exposed or nonexposed to chemical agents. In Proceedings of the Conference on Neuropsychologic Complications of War, 1993: 508-31. Bonyad Publishing Company, 1993.

19 Vafaei B, Seidy A. Study of the prevalence and intensity of depression in 100 devotees with chemical and non-chemical war injuries (30-70\%) of imposed war in Tabriz. J Mil Med 2003; 2: 105-10.

20 Devilly GJ. The psychological effects of a lifestyle management course on war veterans and their spouses. J Clin Psychol 2002; 58: 1119-34.

21 Radfar S, Haghani H, Tavalaei A, Modirian E, Falahati M. Evaluation of mental health state in veterans family (15-18 Y/O adolescents). J Mil Med 2005; 3: 203-9.

22 McCann IL, Pearlman LA. Constructivist self-development theory: a theoretical framework for assessing and treating traumatized college students. J Am Coll Health 1992; 40: 189-96.

23 Motta RW. Secondary trauma. Int J Emerg Ment Health 2008; 10: 291-8.

24 Marriage S, Marriage K. Too many sad stories: clinician stress and coping. Can Child Adolesc Psychiatr Rev 2005; 14: 114-7.
25 Stevens MM, Olson AL, Gaffney CA, Tosteson TD, Mott LA, Starr P. A pediatric, practice-based, randomized trial of drinking and smoking prevention and bicycle helmet, gun, and seatbelt safety promotion. Pediatrics 2002; 109: 490-7.

26 Goldblatt H. Caring for abused women: impact on nurses' professional and personal life experiences. J Adv Nurs 2009; 65: 1645-54.

27 Kleespies PM, Dettmer EL. The stress of patient emergencies for the clinician: incidence, impact, and means of coping. J Clin Psychol 2000; 56: 1353-69.

28 Pross C. Burnout, vicarious traumatization and its prevention. Torture 2006; 16: 1-9.

29 Farrar AR. Vicarious traumatization of the mental health professional. APAGS Newsletter 2002; Winter.

30 Bilal MS, Rana MH, Rahim S, Ali S. Psychological trauma in a relief worker - a case report from earthquake-struck areas of north Pakistan. Prehosp Disaster Med 2007; 22: 458-61.

31 Geller JA, Madsen LH, Ohrenstein L. Secondary trauma: a team approach. Clin Soc Work J 2004; 32: 415-30.

32 Fullerton CS, Ursano RJ. Posttraumatic responses in spouse/significant others of disaster workers. In Posttraumatic Stress Disorder: Acute and Long-term Responses to Trauma and Disaster (eds CS Fullerton \& RJ Ursano): 59-76. American Psychiatric Press, 1997.

33 Figley CR. Strangers at home: comment on Dirkzwager, Bramsen, Adèr and van der Ploeg (2005). J Fam Psychol 2005; 19: 227-9.

34 Figley CR. Burnout in Families: The Systematic Cost of Caring. CRC Press, Taylor \& Francis Group, 1998.

35 Bell H. Strengths and secondary trauma in family violence work. Soc Work 2003; 48: 513-22.

36 Koić $E$, Francišković $T$, Mužinić-Masle L, Đorðević $V$, Vondraček S. Chronic pain and secondary traumatization in wives of Croatian war veterans treated for post traumatic stress Disorder. Acta Clinica Croatica 2002; 41: 295-306

37 Dekel R, Solomon Z, Bleich A. Emotional distress and marital adjustment of caregivers: contribution of level of impairment and appraised burden. Anxiety Stress Coping 2005; 18: 71-82.

38 Solomon Z, Levi G, Waysman M, Fried B, Mikulincer M, Florian V, et al. Secondary traumatization among wives of soldiers with combat stress reaction [in Hebrew]. Harefuah 1993; 124: 750-6, 796.

39 Renshaw KD, Rodrigues CS, Jones DH. Psychological symptoms and marital satisfaction in spouses of Operation Iraqi Freedom veterans: relationships with spouses' perceptions of veterans' experiences and symptoms. J Fam Psychol 2008; 22: 586-94.

40 Dekel R. Posttraumatic distress and growth among wives of prisoners of war: the contribution of husbands' posttraumatic stress disorder and wives' own attachments. Am J Orthopsychiatry 2007; 77: 419-26.

41 Dekel R, Solomon Z. Secondary traumatization among wives of Israeli POWs: the role of POWs' distress. Soc Psychiatry Psychiatr Epidemiol 2006; 41: 27-33.

42 Westerink J, Giarratano L. The impact of posttraumatic stress disorder on partners and children of Australian Vietnam veterans. Aust N Z J Psychiatry 1999; 33: 841-7.

43 Calhoun PS, Beckham JC, Bosworth HB. Caregiver burden and psychological distress in partners of veterans with chronic posttraumatic stress disorder. J Trauma Stress 2002; 15: 205-12.

44 Hendrix CC, Erdmann MA, Briggs K. Impact of Vietnam veterans arousal and avoidance on spouses' perceptions of family life. Am J Fam Ther 1998; 26: 115-28.

45 Jordan BK, Marmar CR, Fairbank J, Schlenger WE, Kulka RA, Hough RL, et al. Problems in families of male Vietnam veterans with posttraumatic stress disorder. J Consult Clin Psychol 1992; 60: 916-26.

46 Bramsen I, Reuling IE, van der Ploeg HM. Indirect traumatization of spouses of Dutch war victims [in Dutch]. Ned Tijdschr Geneeskd 2000; 144: $2210-4$.

47 American Psychiatric Association. Diagnostic and Statistical Manual of Mental Disorders (4th edn) (Text Revision) (DSM-IV-TR). APA, 1994. 
48 Keane TM, Caddell JM, Taylor KL. Mississippi Scale for Combat-Related Posttraumatic Stress Disorder: three studies in reliability and validity. J Consult Clin Psychol 1988; 56: 85-90.

49 Norris FH, Perilla JL. The revised civilian mississippi scale for PTSD: reliability, validity, and cross-language stability. J Trauma Stress 1996; 9 : 285-98.

50 McFall ME, Smith DE, Roszell DK, Tarver DJ, Malas KL. Convergent validity of measures of PTSD in Vietnam combat veterans. Am J Psychiatry 1990; 147: 645-8.

51 Goodarzi MA. Evaluating validity and reliability of Mississippi Post Traumatic Stress disorder Scale. J Psychol 2003; 7: 153-78.

52 Lyons JA, Caddell JM, Pittman RL, Rawls R, Perrin S. The potential for faking on the Mississippi Scale for Combat-Related PTSD. J Trauma Stress 1994; 7: 441-5.

53 Shalev AY, Freedman S, Peri T, Brandes D, Sahar T. Predicting PTSD in trauma survivors: prospective evaluation of self-report and clinicianadministered instruments. Br J Psychiatry 1997; 170: 558-64.

54 Yaffe K, Vittinghoff E, Lindquist K, Barnes D, Covinsky KE, Neylan T, et al. Posttraumatic stress disorder and risk of dementia among US veterans. Arch Gen Psychiatry 2010; 67: 608-13.

55 Zatzick DF, Marmar CR, Weiss DS, Browner WS, Metzler TJ, Golding $\mathrm{JM}$, et al. Posttraumatic stress disorder and functioning and quality of life outcomes in a nationally representative sample of male Vietnam veterans. Am J Psychiatry 1997; 154: 1690-5.

56 Ouimette $\mathrm{P}$, Coolhart D, Sugarman D, Funderburk JS, Zelman RH Dornau C. A pilot study of posttraumatic stress and associated functioning of army National Guard following exposure to Iraq warzone trauma. Traumatol 2008; 14: 51-6.

57 Sayer NA, Noorbaloochi S, Frazier P, Carlson K, Gravely A, Murdoch M Reintegration problems and treatment interests among Iraq and Afghanistan combat veterans receiving VA medical care. Psychiatr Serv 2010; 61: 589-97.

58 Dirkzwager AJE, van der Velden PG, Grievink L, Yzermans CJ. Disasterrelated posttraumatic stress disorder and physical health. Psychosom Med 2007; 69: 435-40.

59 Francisković T, Stevanović A, Jelusić I, Roganović B, Klarić M, Grković J. Secondary traumatization of wives of war veterans with posttraumatic stress disorder. Croat Med J 2007; 48: 177-84.

60 Al-Turkait FA, Ohaer JU. Post-traumatic stress disorder among wives of Kuwaiti veterans of the first Gulf War. J Anxiety Disord 2008; 22: 18-31.

61 Gure TR, Kabeto MU, Blaum CS, Langa KM. Degree of disability and patterns of caregiving among older Americans with congestive heart failure. J Gen Intern Med 2008; 23: 70-6.

62 Evans RL, Bishop DS, Ousley RT. Providing care to persons with physical disability. Effect on family caregivers. Am J Phys Med Rehabil 1992; 71: 140-4.

63 Davis LC, Sander AM, Struchen MA, Sherer M, Nakase-Richardson R, Malec J. Medical and psychosocial predictors of caregiver distress and perceived burden following traumatic brain injury. J Head Trauma Rehabil 2009; 24: 145-54.

\section{Usefulness of reader feedback on the Royal College of Psychiatrists' public information leaflets}

Martin Briscoe, ${ }^{1,2}$ Simon Briscoe, ${ }^{3}$ Philip Timms, ${ }^{2,4}$ Ros Ramsay $^{2,4}$

The Psychiatrist (2011), 35, 175-178, doi: 10.1192/pb.bp.110.030817

${ }^{1}$ Devon Partnership NHS Trust; ${ }^{2}$ Royal College of Psychiatrists Public Education Editorial Board; ${ }^{3}$ Lancashire Teaching Hospitals NHS Foundation Trust: ${ }^{4}$ South London and Maudsley NHS Foundation Trust

Correspondence to Dr M. Briscoe (drmmbriscoe@gmail.com)

First received 13 Apr 2010, final revision 13 Oct 2010, accepted 19 Nov 2010
Aims and method To describe the process for reader feedback on the Royal College of Psychiatrists' online public information leaflets, to report the findings of a retrospective analysis of feedback received over a 14-month period, and to discuss the value of feedback, particularly in relation to the Information Standard quality mark introduced by the Department of Health.

Results We received 38700 completed feedback forms during the period under analysis. We derived scores from the feedback forms, which enabled us to identify those that should be prioritised for review. Written comments from readers highlighted specific areas of the leaflets that required further work.

Clinical implications The development of our public mental health information can be guided using feedback from our readers.

Declaration of interest M.B., P.T. and R.R. are involved in the production and development of the College's online and printed mental health information leaflets.
Providing patient information has become increasingly recognised as an important part of clinical practice. Without it, informed choice about treatments is not possible. Unfortunately, much patient information is written in complex language and is poorly presented. ${ }^{1}$
In an attempt to improve patient information, the Department of Health recently established the Information Standard quality mark (www.theinformationstandard.org). This mark signposts trustworthy information. It is awarded to organisations after assessing their editorial and review 